\title{
Frog tendon structure and its relationship with locomotor modes
}

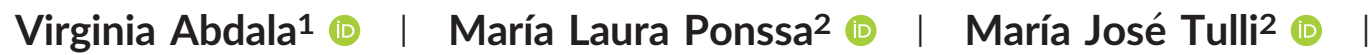 \\ Anne-Claire Fabre ${ }^{3}$ (1) । Anthony Herrel ${ }^{3}$
}

${ }^{1}$ Instituto de Biodiversidad Neotropical UNT-CONICET, Cátedra de Biología General. Universidad Nacional de Tucumán, Tucumán, Argentina

${ }^{2}$ Unidad Ejecutora Lillo, Fundación Miguel Lillo-CONICET, Tucumán, Argentina

${ }^{3}$ Département d'Ecologie et de Gestion de la Biodiversité, 55 rue Buffon, Bat Anatomie Comparee, CP 55, Paris Cedex 5, 75005, France

\section{Correspondence}

Virginia Abdala, Instituto de Biodiversidad Neotropical. Cátedra de Biología General, Facultad de Ciencias Naturales, UNT. 4000 Tucumán, República Argentina.

Email: virginia@webmail.unt.edu.ar

\section{Funding information}

Agencia Nacional de Promoción Científica y Tecnológica, Grant/Award Numbers: FONCYT PICT 2015-1618, FONCYT PICT 2016-2772; Consejo Nacional de Investigaciones Científicas y Técnicas, Grant/Award Number: PIP 0389

\begin{abstract}
Tendon collagen fibrils are the basic force-transmitting units of the tendon. Yet, surprisingly little is known about the diversity in tendon anatomy and ultrastructure, and the possible relationships between this diversity and locomotor modes utilized. Our main objectives were to investigate: (a) the ultra-structural anatomy of the tendons in the digits of frogs; (b) the diversity of collagen fibri diameters across frogs with different locomotor modes; (c) the relationship between morphology, as expressed by the morphology of collagen fibrils and tendons, and locomotor modes. To assess the relationship between morphology and the locomotor modes of the sampled taxa we performed a principal component analysis considering body length, fibrillar cross sectional area (CSA) and tendon CSA. A MANOVA showed that differences between species with different locomotor modes were significant with collagen fibril diameter being the discriminating factor. Overall, our data related the greatest collagen fibril diameter to the most demanding locomotor modes, conversely, the smallest collagen fibril CSA and the highest tendon CSA were observed in animals showing a hopping locomotion requiring likely little absorption of landing forces given the short jump distances.
\end{abstract}

\section{KEYWORDS}

anuran locomotion

\section{1 | INTRODUCTION}

Collagen fibrils are the basic structural elements that withstand tensile forces in the connective tissues across all animal taxa (Ottani, Raspanti, \& Ruggeri, 2001). Although it has previously been reported that collagen fibrils exhibit a wide range of diameters (Parry, Barnes \& Craig, 1978; Vogel \& Koobs, 1989; Ottani et al., 2001), the functional implications of this structural diversity remain poorly understood. It has been suggested that tendon collagen fibrils determine the mechanical properties and function of the tendon as a whole (Parry et al., 1978; Ottani et al., 2001; Rigozzi, Muller, \& Snedeker, 2010; Rigozzi, Stemmer, Müller, \& Snedeker, 2011). Differences in the material properties of the tendon in hind limb muscles of turkeys were related to structural differences (Matson, Konow, Miller, Konow, \& Roberts, 2012). It has also been suggested that tendons with a larger proportion of larger collagen fibril diameters withstand greater tensile forces because of a higher density of intermolecular cross-links (Parry et al., 1978; Parry,
1988; Franchi, Triré, Quaranta, Orsini, \& Ottani, 2007; Galloway, Lalley, \& Shearn, 2013) and a positive relationship between fibril diameter and tendon stiffness has been observed (Vogel \& Koobs, 1989; Kongsgaard et al., 2010; Cheema, Chuo, Sarathchandra, Showan, \& Brown, 2006; Rigozzi et al., 2010). Three studies (Michna \& Hartmann, 1989; Cheema et al., 2006; Kalson et al., 2011) have demonstrated that function is likely to be reflected directly in the diameter and number of the collagen fibrils in the tendons. Thus, the relationship between patterns of collagen fibril diameters and tendon function appears straightforward. As tendon function is conveyed as movement, and tetrapod locomotor modes are also conveying different movements, it could be considered that locomotor modes can be good proxies for differences in movement/function of tendons involved in those locomotor modes.

Although considerable effort has been made to determine the ultrastructure of connective tissues with the aid of electron microscopy (e.g., Parry et al., 1978; Parry \& Craig, 1984; Gill et al., 2004; Svensson et al., 2007; Rigozzi et al. 2011), most of these studies were performed 
to address issues in the fields of sports or veterinary medicine. Yet, this research avenue seems promising to address questions from an ecomorphological perspective. To the best of our knowledge no studies have compared the ultrastructure of tendons among closely related taxa that differ in ecology and locomotor mode, though there is a study from our group that addressed the organization of the collagen fibril within tendons of frogs and lizards in the context of the network theory (Dos Santos et al., 2014).

Anurans are one of the vertebrate groups that have undergone greatest diversification in locomotor modes (Emerson, 1979; Jorgensen \& Reilly, 2013). Different species have evolved to occupy different habitats leading to specialized arboreal, aquatic, terrestrial, and even fossorial forms. Moreover, within each of these categories, generalists and specialists can be observed. For example, arboreal species can be grouped into generalists that are excellent jumpers and climbers and fine-branch specialists that are specialized walkers and climbers but poor jumpers. Similarly, among terrestrial species runners, hoppers, and jumpers can be identified, each faced with different constraints imposed upon the locomotor system. Jumping in frogs and the evolution thereof has been studied in great detail (e.g., Gans \& Parsons, 1966; Emerson, 1978; Zug, 1978; Shubin \& Jenkins, 1995; Nauwelaerts \& Aerts, 2003; Azizi \& Roberts, 2010; Reilly \& Jorgensen, 2011; Herrel, Vasilopoulou-Kampitsi, \& Bonneaud, 2014; Herrel et al., 2016; Lires, Soto, \& Gómez, 2016; Astley, 2016), with interesting studies devoted to landing (Nauwelaerts \& Aerts, 2006; Essner, Suffian, Bishop, \& Reilly, 2010; Azizi, Larson, Abbott, \& Danos, 2014; Ekstrom \& Gillis, 2015; Bijma, Gorb, \& Kleinteich, 2016; Reilly et al., 2015, 2016). During landing the forelimbs and body need to absorb forces that may be up to three times larger than the propulsive forces (Nauwelaerts $\&$ Aerts, 2006). During landing the forelimbs are extended and the hand placed on the substrate fingers first. Although detailed kinematics of the hand during landing are scarce (Nauwelaerts \& Aerts, 2006; Reilly et al., 2016), it is likely that this movement involves significant extension of the finger and hand flexors that need to resist and absorb these landing forces. It has already been shown that tendons act as power attenuators that protect muscles and modulate the energy dissipated by them (Konow, Azizi, \& Roberts, 2011; Konow \& Roberts, 2015). If so, then differences can be expected between species with different modes of locomotion; for example, we expect that species with longer distance jumps have higher landing forces having greater collagen fibril diameters and overall tendon diameters.

Here, we present an analysis of the flexor tendon ultrastructural anatomy, that is, tendon collagen fibril cross sectional area (CSA), and tendon CSA, in frogs with different modes of locomotion. We selected a digital flexor tendon because of the likely role of the flexor tendons in absorbing landing forces, and also because the proximal or distal (digital) sections of the $\mathrm{m}$. flexor digitorum longus are among the most studied tendons in a comparative context (e.g., Vogel \& Koobs, 1989; Michna \& Hartmann, 1989; Patterson-Kane, Wilson, Firth, Parry, \& Goodship, 1997; Watanabe et al., 2005; Dos Santos et al., 2014). We predict that jumpers will possess a larger number of collagen fibrils and a greater collagen fibril and tendon CSA as the flexor tendons of the fingers are used to absorb landing forces (Nauwelaerts \& Aerts, 2006;
Essner et al., 2010). Conversely, we predict that hoppers will show a larger number of the smallest collagen fibrils and a reduced tendon CSA given that they show a bounding gait with very short distance jumps where landing takes place with the forelimb extended (Reilly et al., 2015), likely associated with low landing forces (but see Reilly et al., 2016). Climbers are likely intermediate despite their longdistance jumps as landing in these animals involves the belly in addition to an attachment with the toes of either front or hind limb (Bijma et al., 2016).

\section{2 | MATERIALS AND METHODS}

Electron microscopy analysis was conducted with samples of the flexor tendon of the Digit IV obtained from adults of the jumpers Leptodactylus chaquensis, L. latinasus, the hoppers Rhinella arenarum and Physalaemus biligonigerus, and the climbers Scinax nasicus and Phyllomedusa sauvagii (Appendix 1 in supporting information). This study was approved by the Ethics Committee of Universidad Nacional de Tucumán, Argentina) (Exp. No. 1206 2010).

\section{$2.1 \mid$ Ultrastructural analyses}

Samples were placed overnight in $0.1 \mathrm{~mol} \mathrm{~L}^{-1}$ phosphate buffer with $2.5 \%$ glutaraldehyde and $4 \%$ paraformaldehyde. The tissue was then immersed in $1 \%$ osmium tetroxide, dehydrated in graded acetones, and flat embedded in Epon plastic 812 (Ernest F Fullam, Inc, Latham, NY) in a cross-sectional orientation. Sections $(85 \mathrm{~nm})$ were obtained and stained with $0.25 \%$ lead citrate and $5 \%$ uranyl acetate in $50 \%$ acetone and then observed and photographed in a JEOL100CX transmission electron microscope (CIME, Universidad Nacional de Tucumán, Argentina). Collagen fibril diameters of each species were measured on each micro-graph using Image J 1.44p (Wayne Rasband, National Institutes of Health, USA, http://rsbweb.nih.gov/ij/). Fibrils included in a randomly selected area of $1.5 \times 2 \mu \mathrm{m}$ were counted in each specimen $(N=42)$ and the diameter of each fibril present in the selected area was measured. To characterize diameter distribution, all fibril diameters measured were plotted per species, within class intervals of $30 \mathrm{~nm}$ of the collagen fibril diameter. Based on the density and diameters of the collagen fibrils, the total area of collagen in a surface of comparable size was calculated using the Image Tool 3.0 software. In addition, the CSA of each collagen fibril was obtained by transforming the diameter data into radius, which was squared and multiplied by pi (Appendix 2 in supporting information).

To characterize tendon ultrastructural morphology, the following statistic descriptors were obtained: abundance, estimated as the num ber of fibrils belonging to a size range per species. Diversity (Table 1), which shows the relative abundance of each group of fibrils, and was calculated using the Shannon-Weaver index $\left(H^{\prime}=-\right.$ sum pi In pi); evenness (Table 1), which expresses how evenly the total of fibrils is distributed in each range, calculated with Pielou's evenness index: $J^{\prime}=H^{\prime} /$ $H_{\text {max }}^{\prime} ; H_{\text {max }}^{\prime}=\ln (s)$, where $s$ is number of types of collagen fibrils. $J$ is constrained between 0 and 1 . 
TABLE 1 Diversity (Shanon-Wiever index: $\mathrm{H}^{\prime}$ ) and Equitativity (Pielou's evenness index: $J^{\prime}$ ) of the collagen fibril ranges for each species

\begin{tabular}{lll}
\hline Species & $\mathbf{H}^{\prime}$ & $\mathbf{J}^{\prime}$ \\
\hline Leptodactylus chaquensis & 2.42 & 0.78 \\
\hline Leptodactylus latinasus & 1.77 & 0.57 \\
\hline Phyllomedusa sauvagii & 2.06 & 0.66 \\
\hline Physalaemus biligonigerus & 1.78 & 0.57 \\
\hline Scinax nasicus & 1.65 & 0.53 \\
\hline Rhinella arenarum & 1.73 & 0.56 \\
\hline
\end{tabular}

\section{2 | Histology}

To obtain the CSA of the sampled tendons (supplementary online material, Appendix 2), portions of the flexor tendon of the Digit IV (Figure 1) were dehydrated through a graded ethanol series, cleared in xylenes and embedded in Paraplast. Embedded specimens were sectioned in serial and semi-serial sections of between 5 and $10 \mu \mathrm{m}$. Sections were deparaffinated, hydrated, and stained with Hematoxylin-Eosin (H-E) and Mallory (Azán) Trichromic (modified from Totty, 2002). Tendon CSA was calculated by averaging four histological sections that were traced using Corel Draw (R) Graphics Suite X5 (Corel Corp., Ottawa, Canada) and saved as JPG. The captured images were measured and analyzed using Image J 1.44p (Wayne Rasband, National Institutes of Health, USA, http://rsbweb.nih.gov/ij/); histological sections correspond to the conventional CSA of the tendons. All these procedures were followed because the small size of the tendons prevented us from obtaining a direct measure of their CSA.

\section{3 | Statistical analyses}

The variables were $\log _{10}$-transformed to meet requirements of normality (Zar, 1999). First, we calculated a correlation matrix (Pearson correlations) to see whether variables were correlated. Next, we tested for differences in snout-vent length between locomotor modes using an ANOVA. Given that no differences in snout-vent length were detected we ran a MANOVA on the fibrillar and tendon CSA data to test for

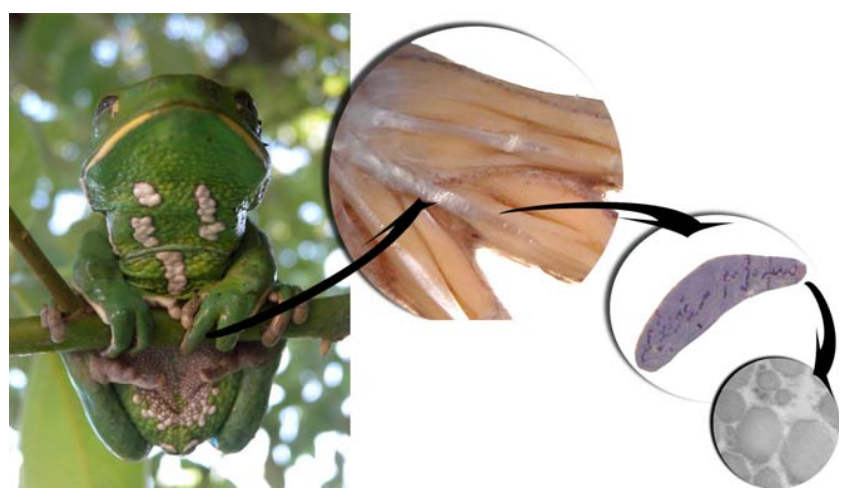

FIGURE 1 Phyllomedusa sauvagii, details of the flexor tendon of the Digit IV, of the CSA of this tendon, and of the CSA of collagen fibril [Color figure can be viewed at wileyonlinelibrary.com]

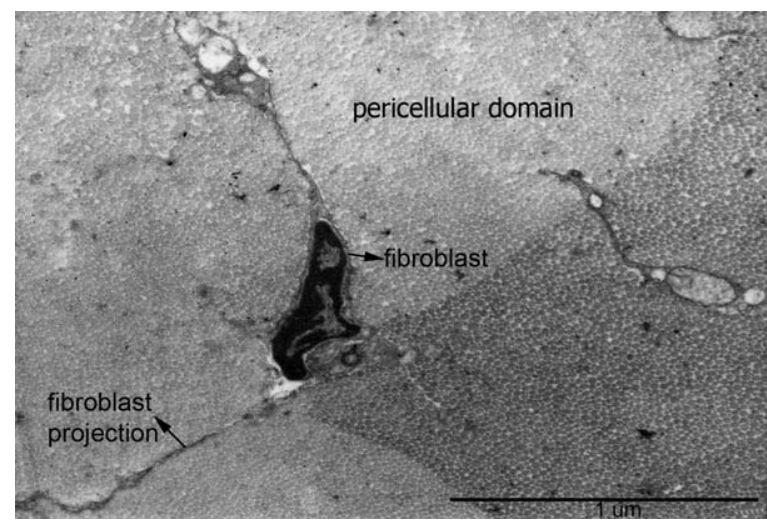

FIGURE 2 Scinax nasicus, transmission electron micrograph of the mature flexor tendon of the Digit IV, showing the fibroblast and the collagen fibers delimited by the projections of the fibroblast

differences between species with different locomotor modes. To explore whether and how phylogeny may impact our data we ran a factor analysis with varimax rotation on the $\log _{10}$-transformed data of snout-vent length, fibrillar CSA, and tendon CSA and plotted the phylogeny in the morphospace using the 'phylomorphospace' function in $\mathrm{R}$ ( $R$ Core Team, 2016) implemented in the 'phytools' library (Revell, 2012). Our cladistic hypothesis of the relationships between species was the phylogeny of Pyron and Wiens (2011). We used the phylogenetic position of the sister taxon L. gracilis to indicate the phylogenetic position of L. latinasus which was not included in the phylogeny.

\section{3 | RESULTS}

\section{1 | Comparative ultrastructural anatomy}

In all samples, the typical tendon configuration of collagen fibers and fibrils is observed. The tendons are composed of collagen fibers delimited by the projections of the fibroblasts, which exhibit a highly retracted cytoplasm characteristic of mature tissue (Figure 2). In all samples, the diameter distribution of collagen fibrils is characteristic of a mature tendon (Figure 2). An extracellular compartmentalization of the collagenous matrix assembly or pericellular domain (Carvalho \& Felisbino, 1999) is observed outside the boundaries of the fibroblast (Figure 2). The fibroblasts and their nuclei are elongated (Figure 3). The nuclei are eccentric, with more heterochromatin than euchromatin. The heterochromatin is located peripherally to the nucleus, surrounded by the euchromatin. The nuclear membrane is perforated by the nuclear pores. In the cytoplasm, large mitochondria, many secretory vacuoles, the Golgi apparatus, and the rough and smooth endoplasmic reticulum are visible (Figure 4). Elongated secretory vacuoles containing procollagen fused in a tandem fashion can be seen, surrounded by a thick layer of mature fibrils. The union between muscle and tendon follows the classic pattern of myotendinous junction (Figure 5), consisting of many variable-sized interdigitations of tendon and muscle (Mair \& Tomé, 1972). The muscle at the myotendinous junction consists of tongues of muscle fibers that surround single or multiple collagen fibrils, which are immersed among the muscular fibers. 


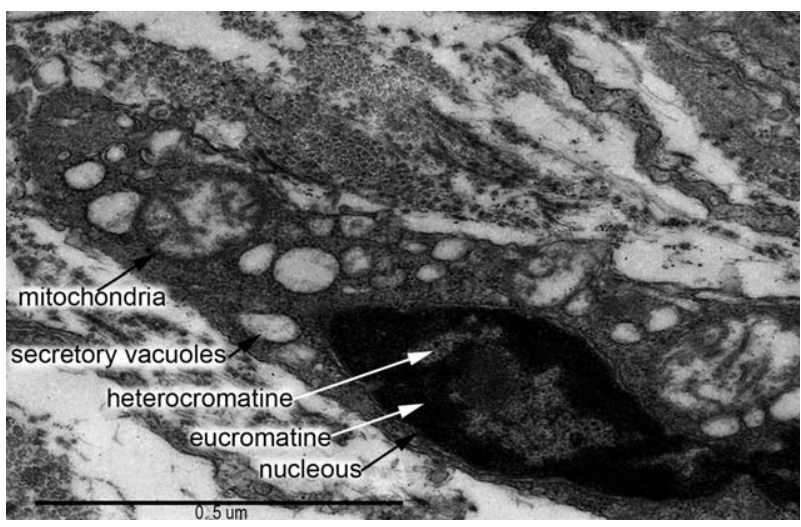

FIGURE 3 Scinax nasicus, transmission electron micrograph of the mature flexor tendon of the Digit IV, showing a fibroblast and its nucleus elongated. The heterochromatin is peripheral to the nucleus, surrounded by the euchromatin. In the cytoplasm, big mitochondria and many secretory vacuoles are visible

The frequency histograms show tendons composed of collagen fibrils of different diameters and in different abundance (Figures 6 and 7). In all taxa, most of the fibrils range from 0 to $100 \mathrm{~nm}$, showing that the smaller fibril diameters occur in highest abundance. The only taxa exhibiting larger collagen fibrillar diameters are Phyllomedusa sauvagii and $L$. chaquensis. These taxa show the maximum values of evenness (Pielou's evenness index) and diversity (Table 1; Figures 6 and 7). The rest of the sampled amphibians exhibit a collagen fibril range smaller than $350 \mathrm{~nm}$. The distribution of the collagen fibril diameters differs among species. For example, in L. chaquensis it is clearly right-skewed (Figure 6).

\section{2 | Statistical analyses}

Our Pearson correlations showed no relationships between snout-vent length and either of the CSA measures. Moreover, the fibrillar CSA was

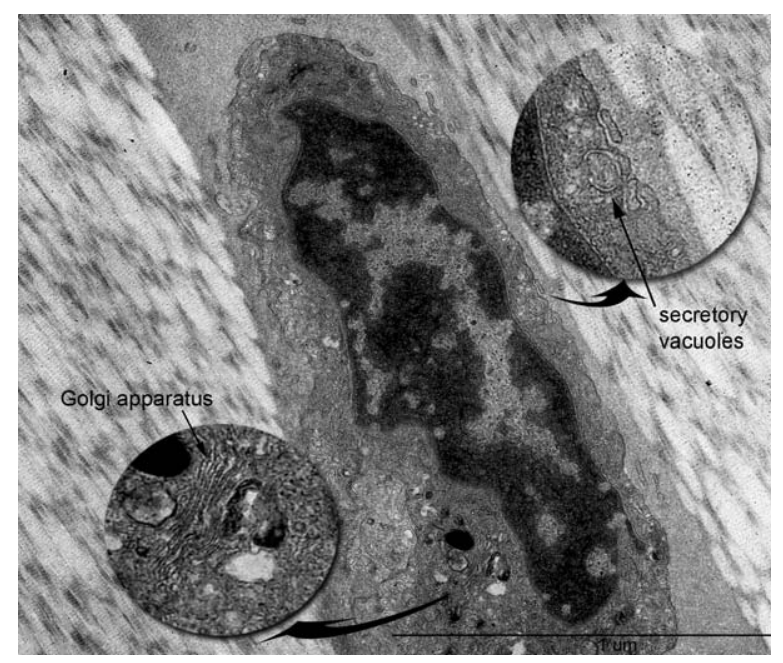

FIGURE 4 Phyllomedusa sauvagii, transmission electron micrograph of the mature flexor tendon of the Digit IV. In the cytoplasm, details of the Golgi apparatus and secretory vacuole. The secretory vacuole fuse in a tandem fashion, similar to compound exocytosis not correlated to the tendon CSA. The factor analysis retained two factors jointly explaining $90 \%$ of the variance in the data set (Figure 8). Whereas the first axis was highly correlated with snout-vent length and tendon CSA, the second axis was strongly correlated with fibrillar CSA. On the plot of the two axes, jumping species clearly segregate along the second axis by having larger scores in contrast to hoppers which have the lowest scores (Figure 8). The phylogeny plotted into the morphospace shows that these data are also somewhat structured by phylogeny (Figure 8).

A univariate analysis of variance showed no differences in snoutvent length between locomotor groups $\left(F_{2,3}=0.41 ; p=.96\right)$. A MANOVA performed on the $\log _{10}$-transformed CSA data showed significant differences between locomotor groups (Wilks' lambda $=0.009$; $\left.F_{4,4}=9.62 ; p=.025\right)$. Subsequent univariate ANOVAs showed that differences were significant only for fibrillar CSA $\left(F_{2,3}=60.89 ; p=.004\right)$. Bonferroni post-hoc tests showed that all locomotor groups differed from one another with jumpers having the highest and hoppers the lowest fibrillar CSA. Arboreal species are intermediate.

\section{4 | DISCUSSION}

Tendons are important sources for storing and recovering elastic energy, minimizing the work that the limb muscles have to do to restore an animal's potential and kinetic energy while running, hopping, or galloping. Tendons are viscoelastic tissues whose elastic properties dominate its overall behavior (Biewener, 2003; Hessel \& Nishikawa, 2017). Roberts, Azizi, \& Abbott, (2011) have shown that muscle properties of frogs are not enough to determine their locomotor performance (see also Roberts \& Azizi, 2011). They found a lack of correlation between available muscle power and jump power, suggesting that nonmuscular mechanisms can obscure the link between muscle mechanical performance and locomotor performance. They proposed that the lack of consistency in their data could be attributed to tendon properties. One very interesting outcome of our work is the correlation analysis

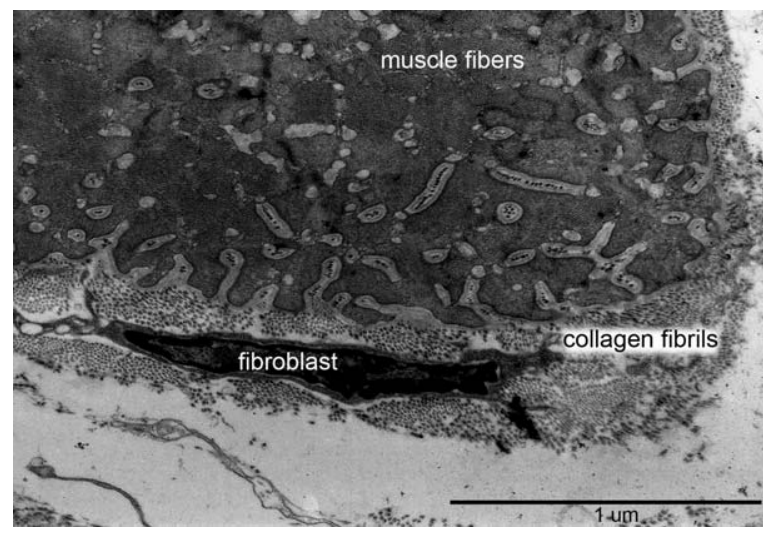

FIGURE 5 Scinax nasicus, transmission electron micrograph of the mature flexor tendon of the Digit IV. Myotendinous junction consisting of many varying sized interdigitations of tendon and muscle. The muscles at the myotendinous junction are visible as tongues of muscle fibers the surround single or multiple collagen fibrils, which are immersed among the muscular fibers 

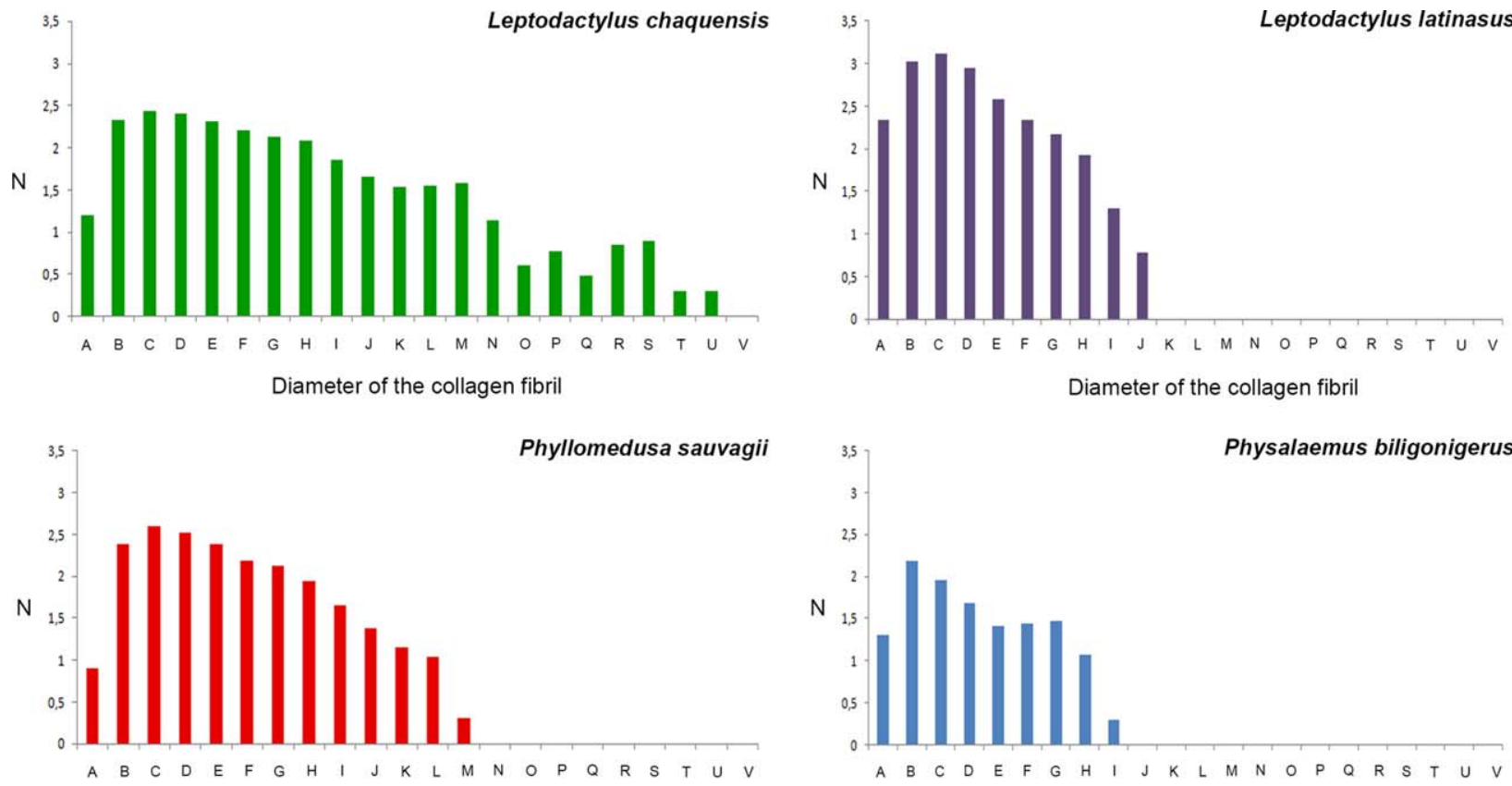

Diameter of the collagen fibril

Diameter of the collagen fibril
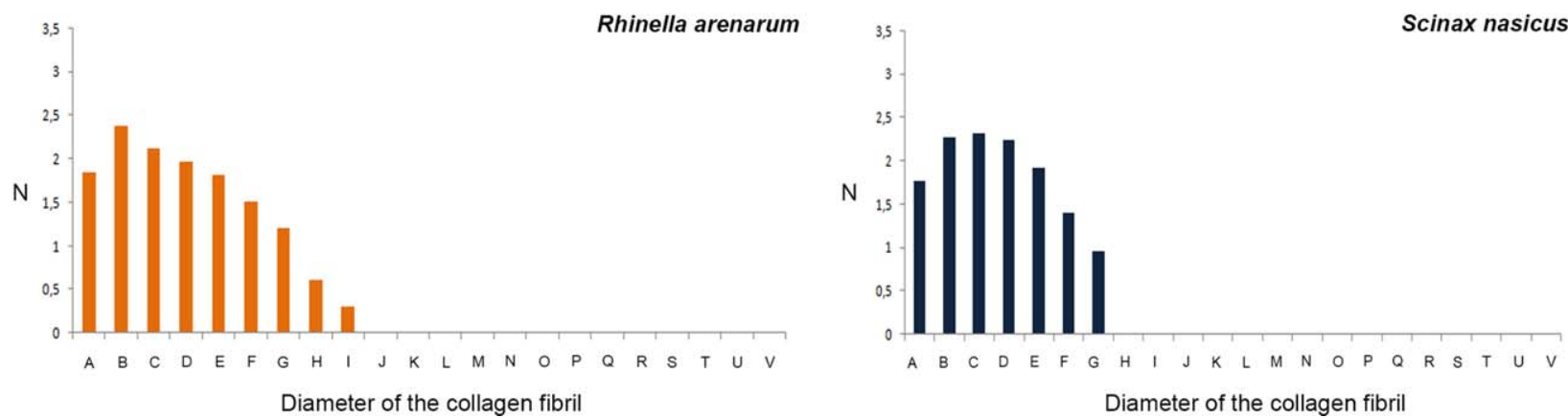

FIGURE 6 Size distribution of collagen fibril diameters of the collagen fibrills from the flexor tendon of the Digit IV. $X$ axis: fibril diameters, each letter (A-V) represents one class interval increasing of $30 \mathrm{~nm}$-that is, A, 10-40 nm; B, 41-70 nm; C, 71-100 nm; D, 101-130 nm; E, 131-160 nm; F, 161-190 nm; G, 191-220 nm; H, 221-250 nm; I: 251-280 nm; J: 281-310 nm; K, 311-340 nm; L: 341-370 nm; M, $371-$ 400 nm; N, 401-431 nm; O, 431-460 nm; P, 461-490 nm; Q, 491-520 nm; R, 521-550 nm; S, 551-580 nm; T, 581-610; U, 611-640 nm; V, $641-670 \mathrm{~nm}$. Y axis: number of fibrils $\log _{10}$ transformed for the sake of clarity [Color figure can be viewed at wileyonlinelibrary.com]

showing that collagen fibrils and tendon diameter are independent of body size. This is an unexpected result because, for example, L. chaquensis, a small sized jumper frog (SVL $78 \mathrm{~mm}$ ) exhibits some of the largest collagen fibril diameters ( $550 \mathrm{~nm}$ ). Reports exist of collagen fibril diameters of horse ( $400 \mathrm{~nm}$; Parry, 1988), rabbit ( $280 \mathrm{~nm}$; Gill et al., 2004), and humans (121 nm; Svensson et al., 2007; Heinemeier \& Kjaer, 2011) all being smaller than those of a small frog. Thus, if body size does not explain the collagen fibril diameter in a tendon, the rationale behind our ecomorphological study is reinforced. The creepinhibition property of a tendon, that is, its ability to resist plastic deformation, has previously been related to the higher percentage of smalldiameter fibrils present (Parry \& Craig, 1984; Parry, 1988; Ottani et al., 2001; Franchi et al., 2007; Galloway et al., 2013). Our results show that almost all analyzed species present a unimodal distribution of collagen diameter. By contrast, two of the species, L. chaquesis and Phyllomedusa sauvagii, exhibiting the broadest ranges of diameters and are those with a unimodal skewed collagen diameter distribution (Parry,
1988; Ameye et al., 2002; Gill et al., 2004). Because the specimens sampled in our work were adults, collagen diameter distribution seems not to be related to ontogenetic aspects of tendon growth. It should be also considered that the observed variation in collagen fibril diameters could be an epiphenomenon of their tapered ends (Trotter \& Koob, 1989; Canty \& Kadler, 2002; Kalson et al., 2011), yet if this were to be the case then a similar broad distribution should be observed in all species if similar sites are examined in the different species.

The taxa showing a skewed-unimodal distribution pattern or the collagen fibrils also exhibit particularities in their movement related behaviors. $P$. sauvagii uses its forelimbs for manipulating prey and during wiping behavior (Gray et al., 1997; Manzano et al., 2008), abilities that require very sophisticated digit movements; L. chaquensis is an exceptional jumper. These are highly demanding movements from a mechanical point of view (Nauwelaerts, Ramsay, \& Aerts, 2007; Manzano et al., 2008). Overall, our data show that frogs tend to exhibit higher values of collagen fibril diameters compared to mammals (Parry, 

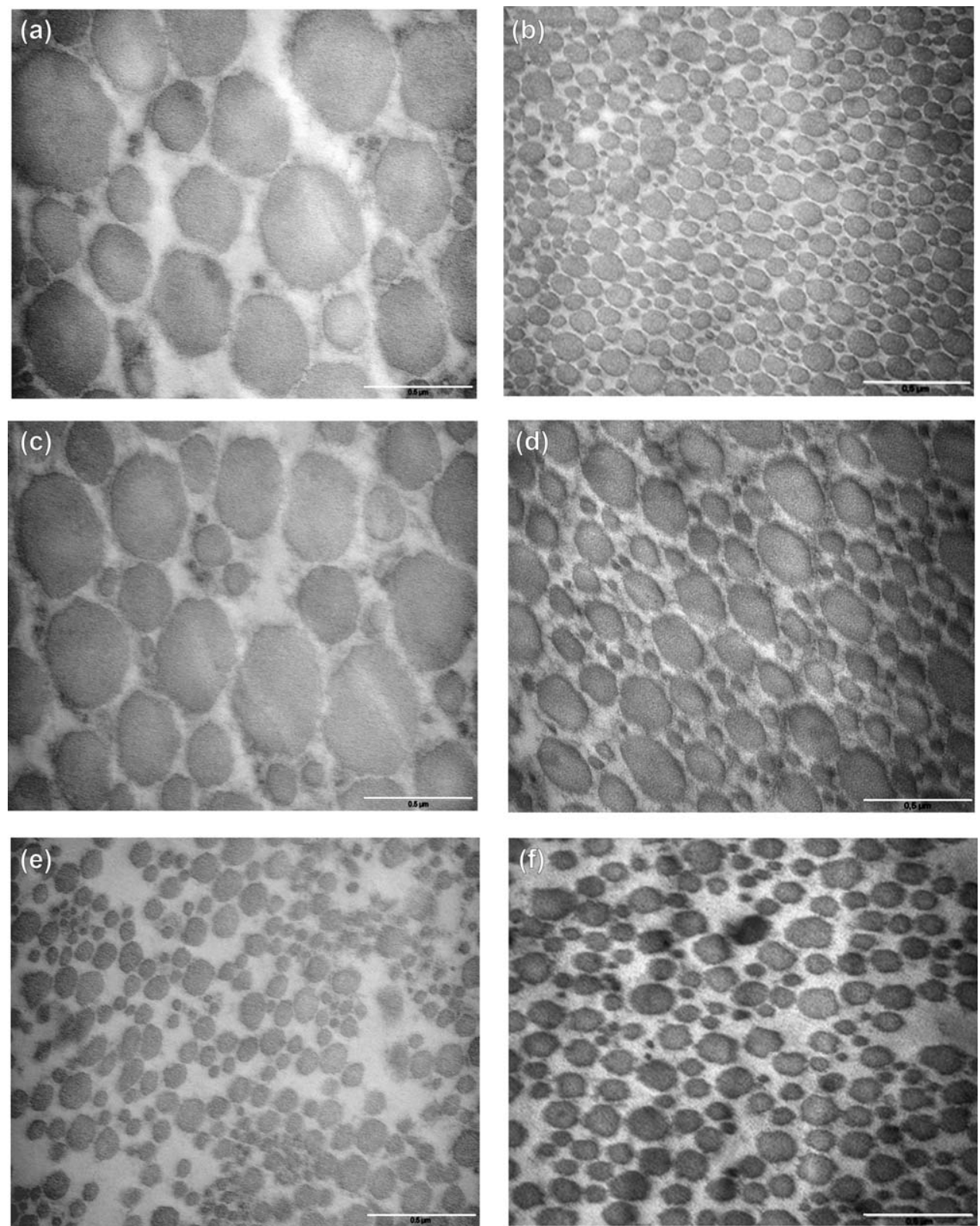

FIGURE 7 Transmission electron microscopic pictures showing transverse sections of the collagen fibrills from the flexor tendon of the Digit IV. (a) Leptodactylus chaquensis (b) Leptodactylus latinasus (c) Phyllomedusa sauvagii (d) Physalaemus biligonigerus (e) Rhinella arenarum (f) Scinax nasicus. Scale bar $0.5 \mu \mathrm{m}$

1988; Ameye et al., 2002; Gill et al., 2004). These data could indicate that terrestrial jumping could have imposed a ancestrally high threshold for the CSA of the tendon collagen fibril.

However, despite the large fibrillar diameter in comparison with other vertebrates, our data also show differences between species with different locomotor modes. Specifically, jumpers had a greater fibrillar CSA than arboreal climbers and jumpers, which in turn had a greater fibrillar CSA than hoppers in line with our predictions. Unexpectedly, however, no differences in tendon CSA were detected between species with different locomotor modes. Moreover, we found no correlation between collagen fibril CSA and tendon CSA confirming that measurements of the tendinous CSA do not per se reflect the collagen content and consequently the functional properties of a tendon (independence of tendon CSA and its functional properties was also highlighted by Magnusson et al., 2003). Our data suggest that variation in collagen fibril dimensions can constitute another important means for tuning mechanical properties of tendons (Matson et al., 2012). The fact that jumpers showed a greater fibrillar CSA suggest that, in line with our prediction, the flexor tendons of the fingers play an important role in absorbing the forces during landing in frogs. Unexpectedly, a study by Reilly et al. (2016) showed higher average forelimb impact forces in a hopper (Rhinella marina) compared to a jumper (Lithobates catesbeiana). However, total landing forces (including body landing forces) for the specialized jumper were nearly higher than those of the hopper (Reilly et al., 2016). Despite the fact that no detailed kinematics of 


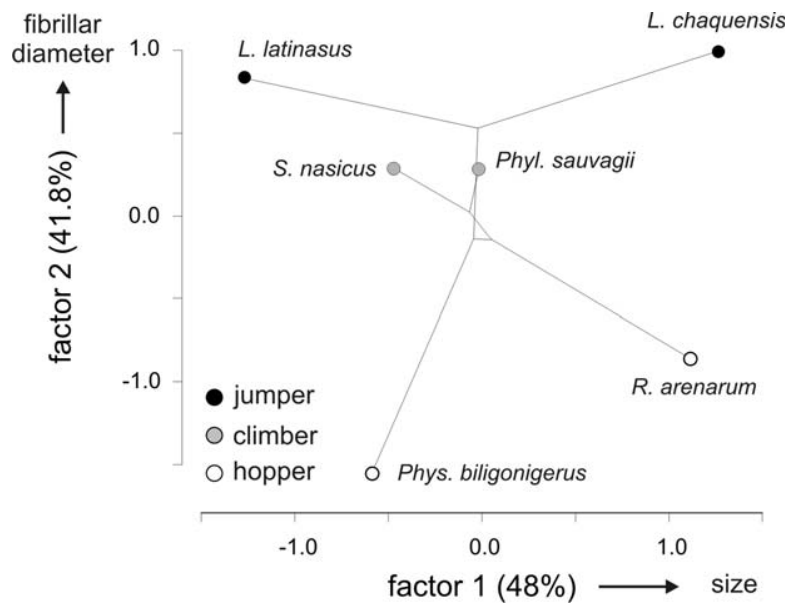

FIGURE 8 Scatterplot illustrating the results of a principal components analysis performed on the tendon measurements and body size. The first axis represents overall frog size and tendon diameter. The second axis explains variation in fibrillar diameter. Frogs with different locomotor modes segregate along the second component with jumpers having the highest fibrillar diameter and hoppers the lowest

the hand and fingers were presented in the paper it appears, however, that the position of the hand is not the same in both species. Future studies would thus benefit from detailed kinematic studies of the hands in different frogs species to better understand the relationships between tendon ultrastructure and function. Moreover, measurements of impact forces for the species studies here would be important in order to validate our prediction suggesting a link between collagen fibril CSA and landing force. In addition, future studies should ground-truth the hypotheses about fibril CSA governing tendon mechanical properties using direct tensile testing as performed in Shadwick (1990), and Matson et al. (2012), among others.

\section{ACKNOWLEDGMENTS}

The authors are deeply indebted to Beatriz Winik, Carolina Santolalla and Manuel Siñeriz of the CIME, Universidad Nacional de Tucumán, and to Alicia Castro, Jorge Mukdsi, and Patricia Pons of Universidad Nacional de Cordoba for their technical assistance. The critical reviews of Daniel Dos Santos (IBN; Universidad Nacional de Tucumán), David Parry (Massey University, New Zealand), Nikolai Konow (UMass Lowell) and one anonimous reviewer are very much appreciated. Grant sponsor: CONICET, PIP 0389; Marie-Skłodowska Curie fellowship, EU project 655694 - GETAGRIP; FONCyT PICT 2015-1618; FONCYT PICT 2016-2772.

\section{ORCID}

Virginia Abdala (D) http://orcid.org/0000-0002-4615-5011

María Laura Ponssa (D) http://orcid.org/0000-0002-8750-9680

María José Tulli (D) http://orcid.org/0000-0003-4763-6973

Anne-Claire Fabre (D) http://orcid.org/0000-0001-7310-1775

Anthony Herrel (D) http://orcid.org/0000-0003-0991-4434

\section{REFERENCES}

Ameye, L., Aria, D., Jepsen, K., Oldberg, A., Xu, T., \& Young, M. F. (2002). Abnormal collagen fibrils in tendons of biglycan/fibromodulindeficient mice lead to gait impairment, ectopic ossification, and osteoarthritis. FASEB Journal, 16, 673-680.

Astley, H. C. (2016). The diversity and evolution of locomotor muscle properties in anurans. Journal of Experimental Biology, 219, 31633173.

Azizi, E., Larson, N. P., Abbott, E. M., \& Danos, N. (2014). Reduce torques and stick the landing: limb posture during landing in toads. The Journal of Experimental Biology, 217(20), 3742-3747.

Azizi, E., \& Roberts, T. J. (2010). Muscle performance during frog jumping: influence of elasticity on muscle operating lengths. Proceedings of the Royal Society, 277(1687), 1523-1530.

Biewener, A. A. (2003). Animal Locomotion. New York: Oxford University Press.

Bijma, N. N., Gorb, S. N., \& Kleinteich, T. (2016). Landing on branches in the frog Trachycephalus resinifictrix (Anura: Hylidae). Journal of Comparative Physiology A, 202, 267-276.

Canty, E. G., \& Kadler, K. E. (2002). Collagen fibril biosynthesis in tendon: A review and recent insights. Comparative Biochemistry and Physiology, Part A, 133(4), 979-985.

Carvalho, H. F., \& Felisbino, S. L. (1999). The development of the pressure-bearing tendon of the bullfrog, Rana catesbeiana. Anatomia Embryologica, 200, 55-64.

Cheema, U., Chuo, C. B., Sarathchandra, P., Showan, N. N., \& Brown, R. A. (2006). Mechanical loading determines collagen fibril diameter independent of cell activity. European Cells and Materials, 11(3), 32.

Dos Santos, D. A., Ponssa, M. L., Tulli, M. J., \& Abdala, V. (2014). Fibrillar organization in tendons: A pattern revealed by percolation characteristics of the respective geometric network. Network Biology, 4(2), 3146.

Ekstrom, L., \& Gillis, G. B. (2015). Pre-landing wrist muscle activity in landing toads. The Journal of Experimental Biology, 218(Pt 15), 24102415.

Emerson, S. B. (1978). Allometry and jumping in frogs: Helping the twain to meet. Evolution; International Journal of Organic Evolution, 32(3), 551-564. https://doi.org/10.2307/2407721

Emerson, S. B. (1979). The iliosacral articulation in frogs: Form and function. Biological Journal of the Linnean Society, 11(2), 153-168.

Essner, R. L., Jr., Suffian, D. J., Bishop, P. J., \& Reilly, S. M. (2010). Landing in basal frogs: Evidence of saltational patterns in the evolution of anuran locomotion. Naturwissenschaften, 97(10), 935-939.

Franchi, M., Triré, A., Quaranta, M., Orsini, E., \& Ottani, V. (2007). Collagen structure of tendon relates to function. The Scientific World Journal, 7, 404-420.

Galloway, M. T., Lalley, A. L., \& Shearn, J. T. (2013). The role of mechanical loading in tendon development, maintenance, injury, and repair. The Journal of Bone and Joint Surgery, 95(17), 1620-1628.

Gans, C., \& Parsons, T. S. (1966). On the origin of the jumping mechanism in frogs. Evolution, 20(1), 92-99. https://doi.org/10.2307/ 2406151

Gill, S. S., Turner, M. A., Battaglia, T. C., Leis, H. T., Balian, G., \& Miller, M. D. (2004). Semitendinosus regrowth biochemical, ultrastructural, and physiological characterization of the regenerate tendon. The American Journal of Sports Medicine, 32, 1173-1181.

Gray, L., O'Reilly, J. C., \& Nishikawa, K. C. (1997). Evolution of forelimb movement patterns for prey manipulation in anurans. Journal of Experimental Zoology, 277, 417-424. 
Heinemeier, K. M., \& Kjaer, M. (2011). In vivo investigation of tendon responses to mechanical loading. Journal of Musculoskeletal \& Neuronal Interactions, 11(2), 115-123.

Herrel, A., Vasilopoulou-Kampitsi, M., \& Bonneaud, C. (2014). Jumping performance in the highly aquatic frog, Xenopus tropicalis: sexspecific relationships between morphology and performance. PeerJournal, 2, e661.

Herrel, A., Moureaux, C., Laurin, M., Daghfous, G., Crandell, K. E., Tolley, K. A., ... Boistel, R. (2016). Frog origins: inferences based on ancestral reconstructions of locomotor performance and anatomy. Fossil Imprint, 72, 108-116.

Hessel, A. L., \& Nishikawa, K. C. (2017). Effects of a titin mutation on negative work during stretch-shortening cycles in skeletal muscles. Journal of Experimental Biology, 220, 4177-4185. https://doi.org/10. 1242/jeb.163204

Järvinen, T. A. H., Jozsa, L., Kannus, P., Järvinen, T. L. N., Kvist, M., Hurme, T., ... Järvinen, M. (1999). Mechanical loading regulates tenascin- $C$ expression in the osteotendinous junction. Journal of Cell Science, 112, 3157-3166.

Jorgensen, M. E., \& Reilly, S. M. (2013). Phylogenetic patterns of skeletal morphometrics and pelvic traits in relation to locomotor mode in frogs. Journal of Evolutionary Biology, 26, 929-943. https://doi.org/ 10.1111/j eb.121 28

Kalson, N. S., Holmes, D. F., Herchenhan, A., Lu, Y., Starborg, T., \& Adler, K. E. (2011). Slow stretching that mimics embryonic growth rate stimulates structural and mechanical development of tendon-like tissue in vitro. Developmental Dynamics, 240(11), 2520-2528.

Kongsgaard, M., Qvortrup, K., Larsen, J., Aagaard, P., Doessing, S., Hansen, P., ... Magnusson, S. P. (2010). Fibril morphology and tendon mechanical properties in patellar tendinopathy effects of heavy slow resistance training. The American Journal of Sports Medicine, 38, 749-756.

Konow, N., Azizi, E., \& Roberts, T. J. (2011). Muscle power attenuation by tendon during energy dissipation. Proceedings of the Royal Society B, 279, 1108-1113. https://doi.org/10.1098/rspb.2011.1435

Konow, N., \& Roberts, T. J. (2015). The series elastic shock absorber: tendon elasticity modulates energy dissipation by muscle during burst deceleration. Proceedings of the Royal Society B, 282(1804), 20142800.

Lires, A., Soto, I. M., \& Gómez, R. O. (2016). Walk before you jump: New insights on early frog locomotion from the oldest known salientian. Paleobiology, 42, 612-623.

Magnusson, S. P., Beyer, N., Abrahamsen, H., Aagaard, P., Neergaard, K., \& Kjaer, M. (2003). Increased cross-sectional area and reduced tensile stress of the achilles tendon in elderly compared with young women. Journal of Gerontology: Biological Sciences, 58A, 123-127.

Mair, W. G. P., \& Tomé, F. M. S. (1972). The ultra-structure of the adult and developing human myotendinous junctions. Acta Neuropathologica, 21, 239-252.

Matson, A., Konow, N., Miller, S., Konow, P. P., \& Roberts, T. J. (2012). Tendon material properties vary and are interdependent among turkey hindlimb muscles. The Journal of Experimental Biology, 215(20), 3552-3558. http://doi.org/10.1242/jeb.072728

Michna, H., \& Hartmann, G. (1989). Adaptation of tendon collagen to exercise. International Orthopaedics, 13(3), 161. https://doi.org/10. 1007/BF0026804

Nauwelaerts, S., \& Aerts, P. (2003). Propulsive impulse as a covarying performance measure in the comparison of the kinematics of swimming and jumping in frogs. Journal of Experimental Biology, 206(23), 4341-4351. https://doi.org/10.1242/jeb.00690

Nauwelaerts, S., \& Aerts, P. (2006). Take-off and landing forces in jumping frogs. The Journal of Experimental Biology, 209(Pt 1), 66-77.
Nauwelaerts, S., Ramsay, J., \& Aerts, P. (2007). Morphological correlates of aquatic and terrestrial locomotion in a semi-aquatic frog, Rana esculenta: no evidence for a design conflict. Journal of Anatomy, 210(3), 304-317.

Ottani, V., Raspanti, M., \& Ruggeri, A. (2001). Collagen structure and functional implications. Micron (Oxford, England: 1993), 32(3), 251-260.

Parry, D. A. D. (1988). The molecular and fibrillar structure of collagen and its relationship to the mechanical properties of connective tissue. Biophysical Chemistry, 29(1-2), 195-209.

Parry, D. A. D., Barnes, G. R., \& Craig, A. S. (1978). A comparison of the size distribution of collagen fibrils in connective tissues as a function of age and a possible relation between fibril size distribution and mechanical properties. Proceedings of the Royal Society London B. Biological Sciences, 203, 305-321.

Parry, D. A. D., \& Craig, A. S. (1984). Growth and development of collagen fibrils in connective tissue. In A. Ruggeri \& P. M. Motta (Eds.), Ultra-structure of the connective tissue matrix (pp. 34-64). Boston: Martinus Nijhoff.

Patterson-Kane, J. C., Wilson, A. M., Firth, E. C., Parry, D. A. A., \& Goodship, A. E. (1997). Comparison of collagen fibril populations in the superficial digital flexor tendons of exercised and nonexercised Thoroughbreds. Equine Veterinary Journal, 29, 121-125.

Pyron, R. A., \& Wiens, J. J. (2011). A large-scale phylogeny of Amphibia including over 2800 species, and a revised classification of extant frogs, salamanders, and caecilians. Molecular Phylogenetics and Evolution, 61, 543-583.

R Core Team (2016). R: A Language and Environment for Statistical Computing. Vienna: R Foundation for Statistical Computing. http://www. R-project.org.

Reilly, S. M., \& Jorgensen, M. E. (2011). The evolution of jumping in frogs: morphological evidence for the basal anuran locomotor condition and the radiation of locomotor systems in crown group anurans. Journal of Morphology, 272(2), 149-168. https://doi.org/10.1002/jmor.10902

Reilly, S. M., Montuelle, S. J., Schmidt, A., Naylor, E., Jorgensen, M. E., Halsey, L. G., \& Essner, R. L. Jr. (2015). Conquering the world in leaps and bounds: hopping locomotion in toads is actually bounding. Functional Ecology, 29, 1308-1316.

Reilly, S. M., Montuelle, S. J., Schmidt, A., Krause, K., Naylor, E., \& Essner, R. L. Jr. (2016). Functional evolution of jumping in frogs: interspecific differences in take-off and landing. Journal of Morphology, 277, 379-2393.

Revell, L. J. (2012). Phytools: an R package for phylogenetic comparative biology (and other things). Methods in Ecology and Evolution, 3(2), 217-223.

Rigozzi, S., Muller, R., \& Snedeker, J. G. (2010). Collagen fibril morphology and mechanical properties of the Achilles tendon in two inbred mouse strains. Journal of Anatomy, 216, 724-731.

Rigozzi, S., Stemmer, A., Müller, R., \& Snedeker, J. G. (2011). Mechanical response of individual collagen fibrils in loaded tendon as measured by atomic force microscopy. Journal of Structural Biology, 176(1), 9-15.

Roberts, T. J., \& Azizi, E. (2011). Flexible mechanisms: the diverse roles of biological springs in vertebrate movement. The Journal of Experimental Biology, 214(3), 353-361.

Roberts, T. J., Azizi, E., \& Abbott, E. M. (2011). The weak link: do muscle properties determine locomotor performance in frogs? Philosophical Transactions Royal Society London B. Biological Sciences, 366(1570), 1488-1495.

Shadwick, R. E. (1990). Elastic energy storage in tendons: Mechanical differences related to function and age. Journal of Applied Physiology, 68 (3), 1033-1040.

Shubin, N. H., \& Jenkins, F. A. (1995). An Early Jurassic jumping frog. Nature, 377(6544), 49-52. https://doi.org/10.1038/377049a0

Svensson, M., Movin, T., Rostgård-Christensen, L., Blomén, E., Hultenby, K., \& Kartus, J. (2007). Ultrastructural collagen fibril alterations in the 
patellar tendon 6 years after harvesting its central third. American Journal of Sports Medicine, 35, 301-306.

Totty, B. A. (2002). Mucins. In J. D. Bancroft \& M. Gamble (Eds.), Theory and practice of histological techniques (pp. 163-200). Edinburgh: Churchill Livinston Press.

Trotter, J. A., \& Koob, T. J. (1989). Collagen and proteoglycan in a sea urchin ligament with mutable mechanical properties. Cell and Tissue Research, 258(3), 527-539.

Vogel, K. G., \& Koobs, T. J. (1989). Structural Specialization in Tendons under Compression. International Review of Cytology, 115, 267-293.

Watanabe, T., Hosaka, Y., Yamamoto, E., Ueda, H., Sugawara, K., Takagashi, H., \& Takehana, K. (2005). Control of the collagen fibril diameter in the equine superficial digital flexor tendon in horses by Decorin. Journal of Veterinary Medical Science, 67, 855-870.

Zar, J. H. (1999). Biostatistical analysis. Upper Saddle River, NJ: PrenticeHall.
Zug, G. R. (1978). Anuran locomotion-structure and function, 2, jumping performance of semiaquatic, terrestrial and arboreal frogs. Smithsonian Contributions in Zoology, 276, 1-31. https://doi.org/10.5479/si.00810282.276

\section{SUPPORTING INFORMATION}

Additional Supporting Information may be found online in the supporting information tab for this article.

How to cite this article: Abdala V, Ponssa ML, Tulli MJ, Fabre A-C, Herrel A. Frog tendon structure and its relationship with locomotor modes. Journal of Morphology. 2018;00:1-9. https:// doi.org/10.1002/jmor.20819 